\title{
ANALYSIS OF DEFORMATIONS OF THE SKYLIGHT CONSTRUCTION AT THE MAIN HALL OF THE WARSAW UNIVERSITY OF TECHNOLOGY
}

\author{
Waldemar Odziemczyk \\ Faculty of Geodesy and Cartography, \\ Warsaw University of Technology \\ Warsaw, Poland
}

\begin{abstract}
The paper presents technology and results of measurements of the steel construction of the skylight of the Main Hall of the Warsaw University of Technology. The new version of the automated measuring system has been used for measurements. This system is based on Leica TCRP1201+ total station and the TCcalc1200 software application, developed by the author, which operates on a laptop computer connected with the total station by the wire. Two test measurements were performed. Each of them consisted of cyclic measurement using the polar method, from one station; points located on the skylight construction, as well as control points located on concrete, bearing poles, were successively measured'. Besides geometrical values (such as $\mathrm{Hz}, \mathrm{V}$ angles and the slope distance $\mathrm{D}$ ), the changes of temperature and atmospheric pressure, were also recorded. Processed results of measurements contained information concerning the behaviour of the skylight; asymmetry of horizontal displacements with respect to the $X$ axis have been proved. Changes of parameters of the instrument telescope and changes of the instrument orientation were also stated; they were connected with changes of the temperature. The most important results of works have been presented in the form of diagrams.
\end{abstract}

Keywords: TPS1200, Total Station, automation

\section{Introduction}

The skylight of the Main Hall of the Warsaw University of Technology is an example of the steel construction (Fig. 2). Such constructions, similarly to the roof of the amphitheater in Koszalin, described by Deska K. (2013), are usually sensitive for changes of temperature. In the case of a skylight this effect increases because it consists of two roof coats: an outer coat made of transparent glass and the inner coat, which is constructed of matt, plastic elements. The space between those coats 
is called the inter-roof. The bearing construction of the skylight is made of steel bevels. Besides these elements, two inspection platforms and a set of lamps, which illuminate the Main Hall, have been mounted on the bearing construction. The closed space of the inter-roof is particularly sensitive to the greenhouse effect, which may be observed as the high increase of temperature under the influence of the sunlight.

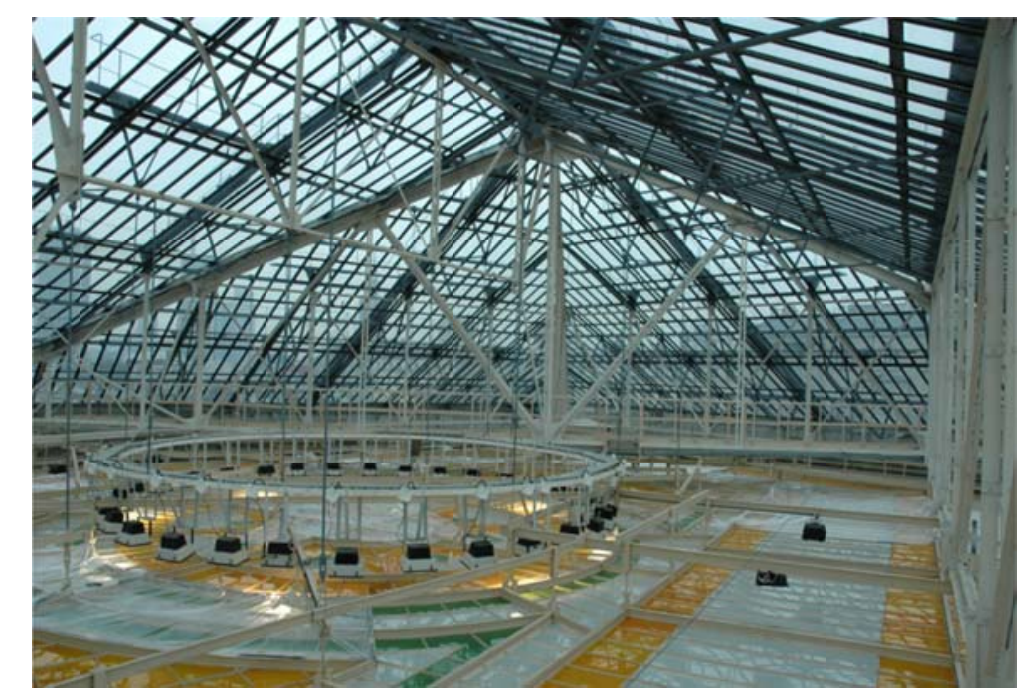

Fig. 1. The skylight of the Main Hall of the Warsaw University of Technology.

Due to the accessibility and the possibility to ensure the safety of measuring equipment, which is left in the skylight (only authorised person may enter this area), this skylight was the subject of many measurements, which mostly aimed at testing various technologies of measurements. The course and results of measurements were described by Jastrzębski S. et al. (2008) or Odziemczyk W., Woźniak M. (2009).

This paper presents the technology and results of measurements of the steel construction of the skylight, performed with the use of an automated measuring system, which is based on the Leica TCRP1201+ total station and TCcalc1200 software tool developed by the author.

\section{The automated measuring system}

Within the frames of research works, performed at the Faculty of Geodesy and Cartography an automated measuring system was developed, which utilises the automated TPS1200 series total station and the laptop computer, as a platform for the controlling software tool, called TCcalc1200 (Fig. 2). The computer is connected with the instrument by a standard socket of the total station (Lemo type) and the serial socket RS232. Connection is usually performed by the cable, although successful attempts to substitute the cable with a pair of radio-modems were also performed.

The controlling tool, TCcalc1200 has been developed as the extension of the previous application, called TCcalc, which is presented in (Odziemczyk W., Woźniak M. (2008). The general assumptions of this application were the subject of a separate paper (Odziemczyk W. 2012). The application allows to perform the following measuring procedures: 
- determination of the position of the station basing on measurements of reference points,

- measurements of the object points in the manual mode,

- measurements of the object points in the semi-automatic mode,

- measurements of the object points in the automatic mode, using ATR function.

Measurements performed in the semi-automatic and automatic modes require the knowledge of approximate positions of points. Measurements in the automatic mode may be performed only for points which are marked with return reflectors. Measurements of deformations of the skylight construction were performed in the automatic mode. This procedure consists of cycles of successive measurements of all points of the object in two positions of the circle. Besides measured geometric values the time of measurement is also recorded for each measurement.

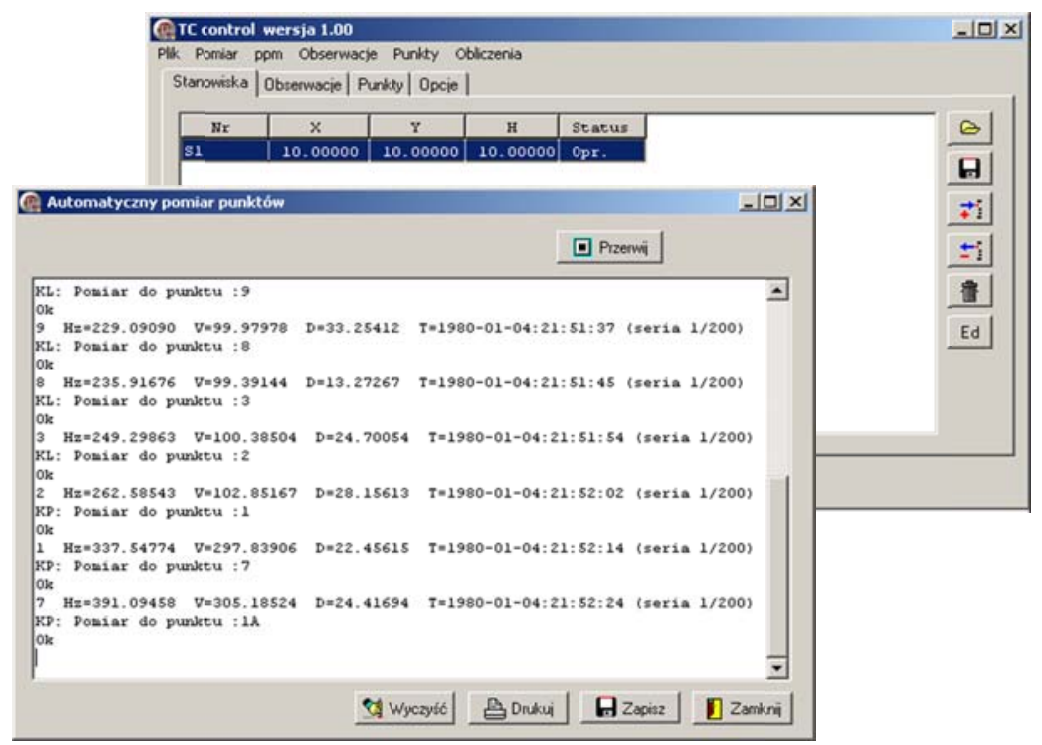

Fig. 2. Windows of the TCcalc1200 controlling application

In order to achieve the maximum accuracy of determination of displacements, distances to controlled points of the construction, measured by means of the total station, should be corrected by the influence of temperature and atmospheric pressure. The EXTECH RH520A (Fig.3) recorder was used to record temperature. The atmospheric pressure value was read-out from the barometer. Corrections of particular observations may be calculated basing on temperature variations, during relevant procedures of TCcalc1200 software tool.

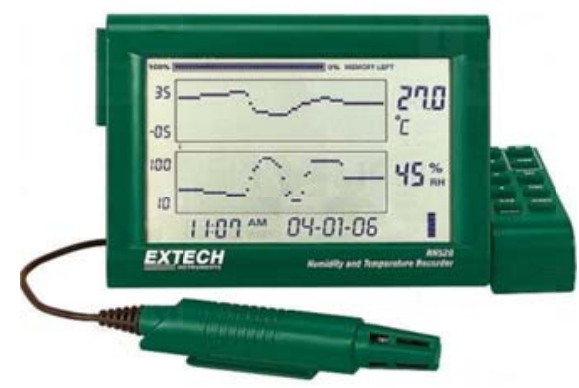

Fig. 3. EXTECH RH520A recorder 
Besides, this tool offers a series of procedures for data management and procedures of computations, which allow for easy controlling the results, introducing required corrections and calculating spatial coordinates of observed points in prticular measurements.

\section{Measurements of deformations of the skylight construction}

In order to investigate movements of the skylight construction, seven prismatic reflectors were mounted on steel construction elements; they were considered as control points. Locations of those reflectors are presented in Fig.4.

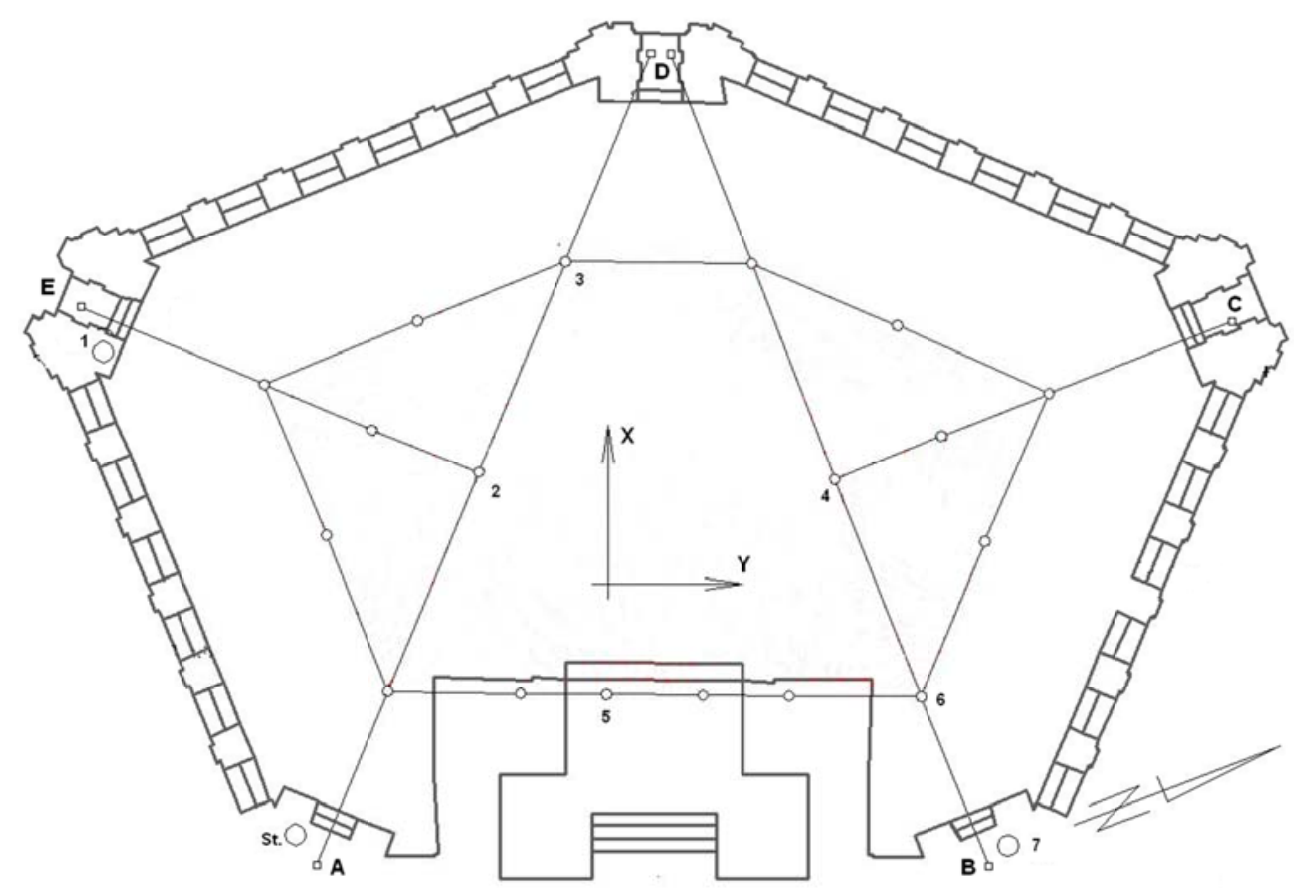

Fig. 4. Locations of the station and control points

The total station (St) and two control points (1 and 7) were placed on Bearing supports of the construction. Remaining points were assembled to steel construction elements. The air temperature was recorded in a shadowed place close to the total station.

Results of two session, selected from performed sessions of measurements, will be presented below:

- session I October 22 - 24,2012

- session II May 16 - 17, 2013

The session I was longer - it lasted for 48 hours. The session II was a one-day session. Each session consisted of cycles of measurements, which covered all control points. Every measurement was performed in a full cycle (two faces measurement). The time interval between measurements was equal to 30 minutes In every cycle. The time of measurements of all points in the complete cycle equalled to approx.125 sec. Further it was assumed that the object may be considered immovable within such a short time. Therefore all effects resulting from time expansion of individual measurements were neglected. 
The session I was performed the conditions of relatively small temperature variations $\left(11.5-19.6^{\circ} \mathrm{C}\right)$. During the session II the temperature varied between 21.2 to $46.3^{\circ} \mathrm{C}$. Therefore results obtained In this session will be more interesting.

\section{Determination of displacements of points on the skylight construction}

In order to determine displacements of points of the skylight construction the local coordinate system was assumed. The station of the instrument, understood as the section of the main axis of the instrument and the horizontal axis of the telescope had the coordinates $(0,0,0)$; the orientation of the OY axis was defined accordingly to the direction of the collimation axis to the point 7 (Fig. 4).

The first stage of processing results of measurements consisted of averaging the pointing in particular series of measurements. This allows to eliminate instrumental errors (collimation and the zero point of the vertical circle) and, at the same time, to control particular pointing operations (collimation and zero points should have stable values). The averaging process concerned measured values and the time of measurements. During the next stage, the stability of the total station station was checked. Points 1 and 7, located on the supports of the skylight construction were used for that purpose. As a result, the relative stability of the station was proved with respect to $X$ and $Y$ coordinates; considerable variations in the orientation fo the horizontal circle were also detected. This phenomenon will be described in more details in section 5 .

The successive stage of work consisted of introduction of corrections to measured distances, related to the temperature and the atmospheric pressure. Temperature variations, recorded by means of the EXTECH RH520A recorder and introduced in the TCcalc1200 application were used for that purpose. The atmospheric pressure value was read out from the barometer; it was assumed as constant for the entire measurements. Since the cycle of temperature recording was not correlated with the time of measurements, determination fo the temperature for particular observations required interpolation. It was performed by means of one of the procedures of the software application.

The last stage of works consisted of determination of spatial coordinates of points on the skylight construction, for averaged moments of measurements of particular points, in particular series.

Coordinates of points were calculated basing the following relations:

where:

$$
\begin{array}{cc}
X=X_{0}+d & \cos A \\
Y=Y_{0}+d & \sin A \\
Z=Z_{0}+d & \operatorname{ctg} V
\end{array}
$$

$X, Y, Z$ - coordinates of the total station,

$d$ - horizontal distance,

A - azimuth of the direction to the point being determined,

$\mathrm{V}$ - zenithal angle to the point being determined.

The horizontal distance is calculated from the relation:

$$
d=s \sin V
$$

where:

$\mathrm{s}-$ the inclined distance after introduction of the correction due to atmospheric conditions. 
Due to the small size of the object (the maximum length of the sight line equaled to $33 \mathrm{~m})$ the influence of the Earth curvature was neglected.

In order to estimate the accuracy of determined coordinates, the following mean errors of the $\mathrm{s}$ distance measurements, the $\mathrm{Hz}$ horizontal angle and the $\mathrm{V}$ zenithal angle measurements, were assumed:

$$
\mathrm{m}_{\mathrm{s}}= \pm 0.3 \mathrm{~mm} \quad \mathrm{~m}_{\mathrm{Hz}}= \pm 10^{\mathrm{cc}} \quad \mathrm{m}_{\mathrm{V}}= \pm 10^{\mathrm{cc}}
$$

The mean error of the horizontal distance is described by the formula:

$$
m_{d}=\sqrt{\sin (V)^{2} m_{s}^{2}+\cos (V)^{2} m_{V}^{2}}
$$

After substitution of the assumed errors and the minimum zenithal angle $\left(90^{g}\right)$, which occurs in the measurements, one obtains $m_{d}= \pm 0.296 \mathrm{~mm}$; this allows for making the simplifying assumption $m_{d} \approx m_{s}$.

As a result, mean errors of coordinates may be expressed as the following relations:

$$
\begin{aligned}
& m_{X}=\sqrt{\cos ^{2}(A) m_{d}^{2}+d^{2} \sin ^{2}(A) m_{H z}^{2}} \\
& m_{Y}=\sqrt{\sin ^{2}(A) m_{d}^{2}+d^{2} \cos ^{2}(A) m_{H z}^{2}} \\
& m_{Z}=\sqrt{\cos ^{2}(V) m_{s}^{2}+s^{2} \sin ^{2}(V) m_{V}^{2}}
\end{aligned}
$$

It may be easily checked, that for the current assumptions and for the longest sight line $(d=33 \mathrm{~m})$ mean errors of coordinates $X, Y$ and $Z$ will obtain the maximum values of $0.5 \mathrm{~mm}$

Diagrams presenting changes of coordinates in $\mathrm{mm}$ for particualr points are presented in successive parts of the paper.

\subsection{Session I}

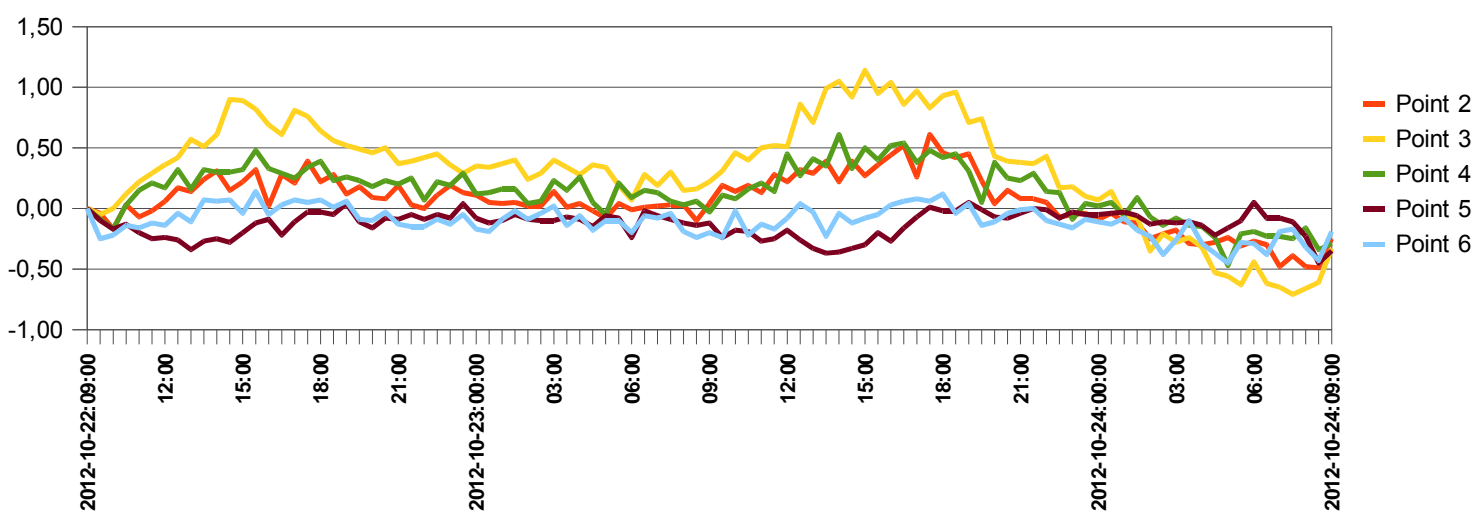

Fig. 5. Horizontal displacements of control points (X coordinate) 


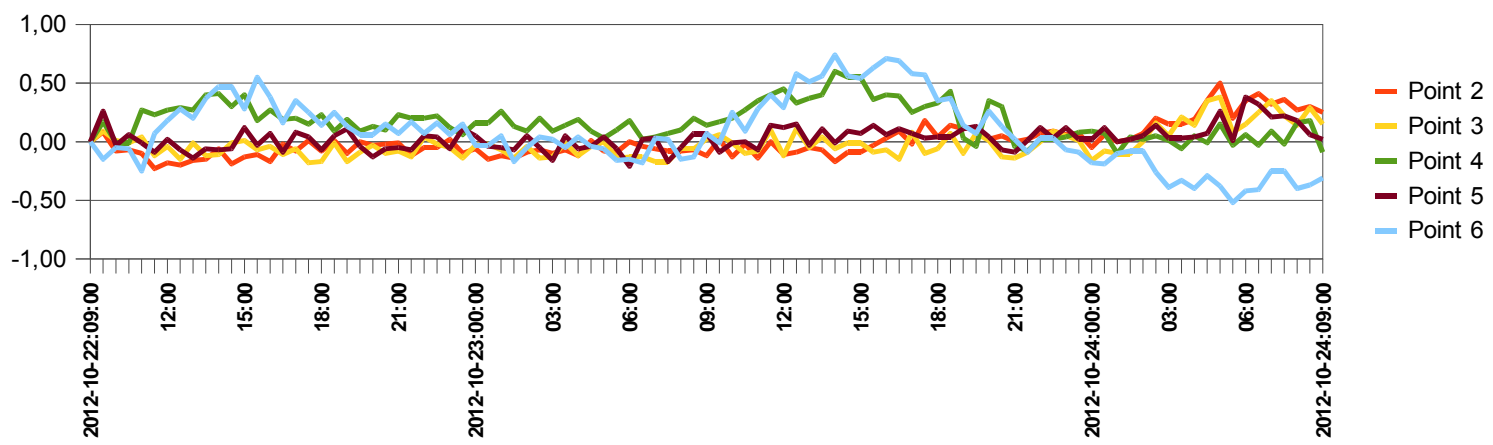

Fig. 6. Horizontal displacements of control points ( $Y$ coordinate)

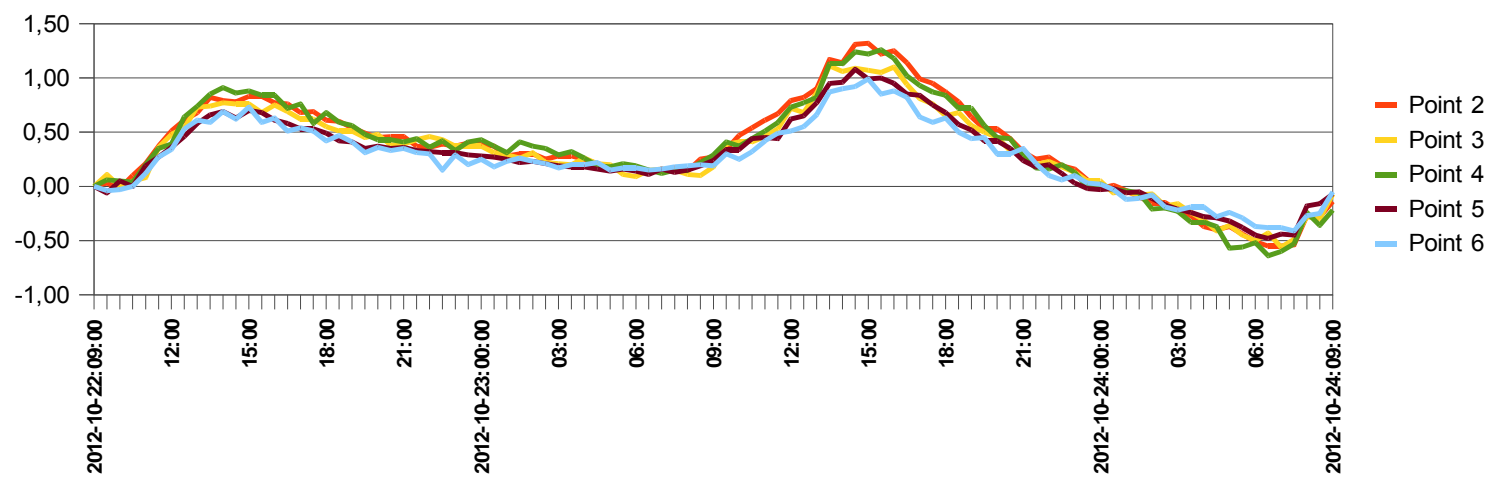

Fig. 7. Vertical displacements of control points ( $Z$ coordinate)

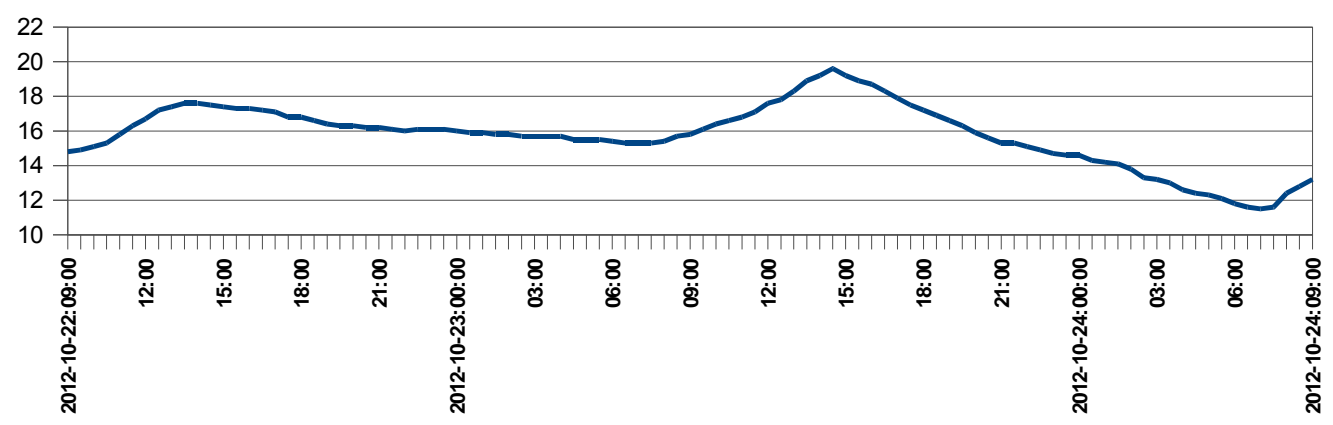

Fig. 8. Changes of temperature in ${ }^{\circ} \mathrm{C}$

Temperature variations during this session were relatively small; however the reaction of the object on these variations may be easily noticed. This concerns, in particular, the $Z$ coordinate, where the amplitude of movements reaches $2 \mathrm{~mm}$; points behave similarly and independently on the point location of the skylight construction. In the case of $X$ and $Y$ coordinates, changes are much smaller and their nature depends on locations of points on the skylight construction. 


\subsection{Sesion II}

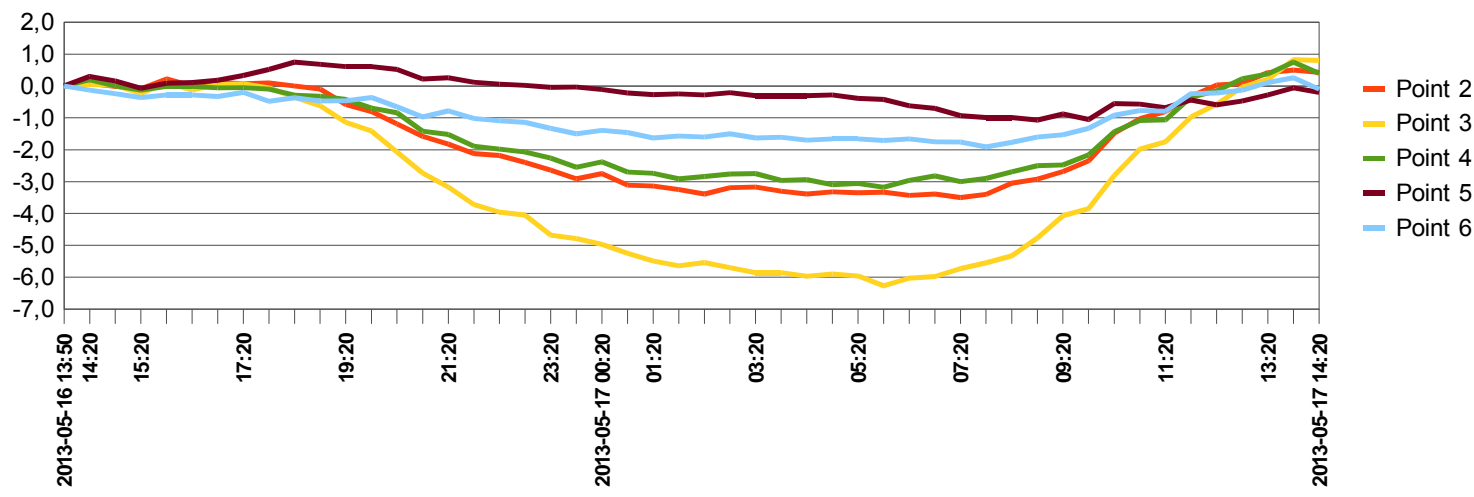

Fig. 9. Horizontal displacements of control points (X coordinate)

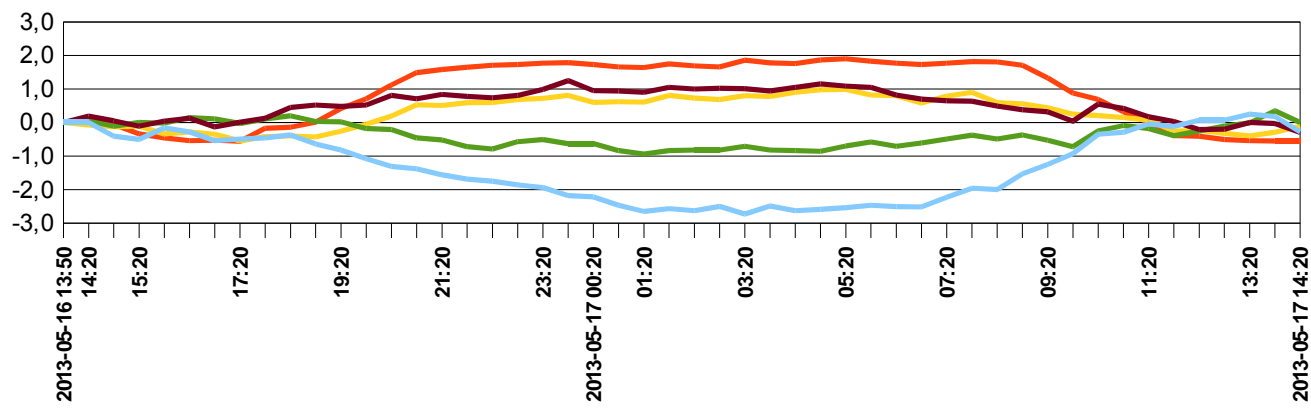

- Point 2

- Point 3

- Point 4

- Point 5

- Point 6

Fig. 10. Horizontal displacements of control points ( $\mathrm{Y}$ coordinate)

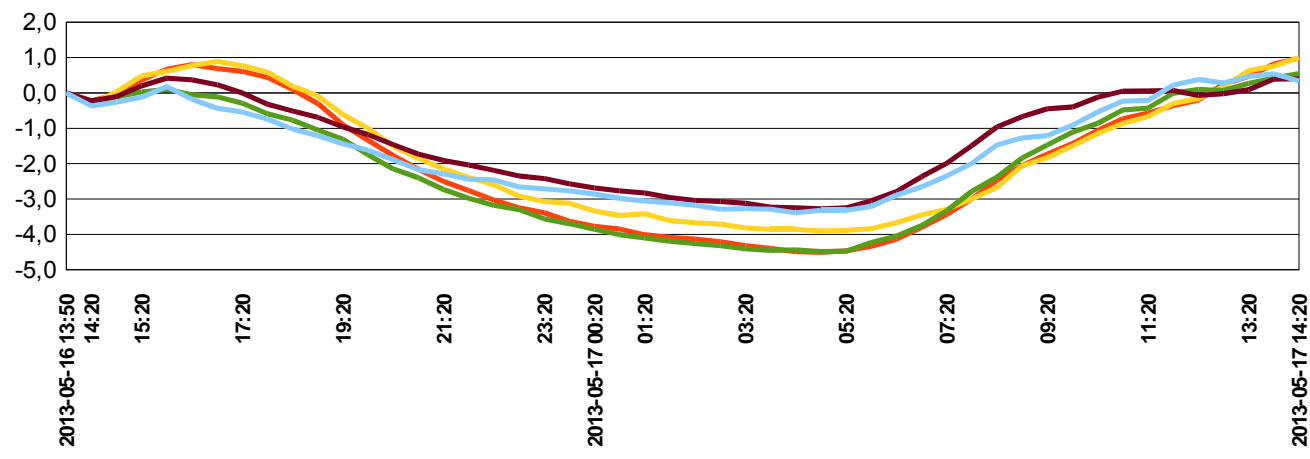

- Point 2

- Point 3

- Point 4

- Point 5

- Point 6

Fig. 11. Vertical displacements of control points ( $Z$ coordinate)

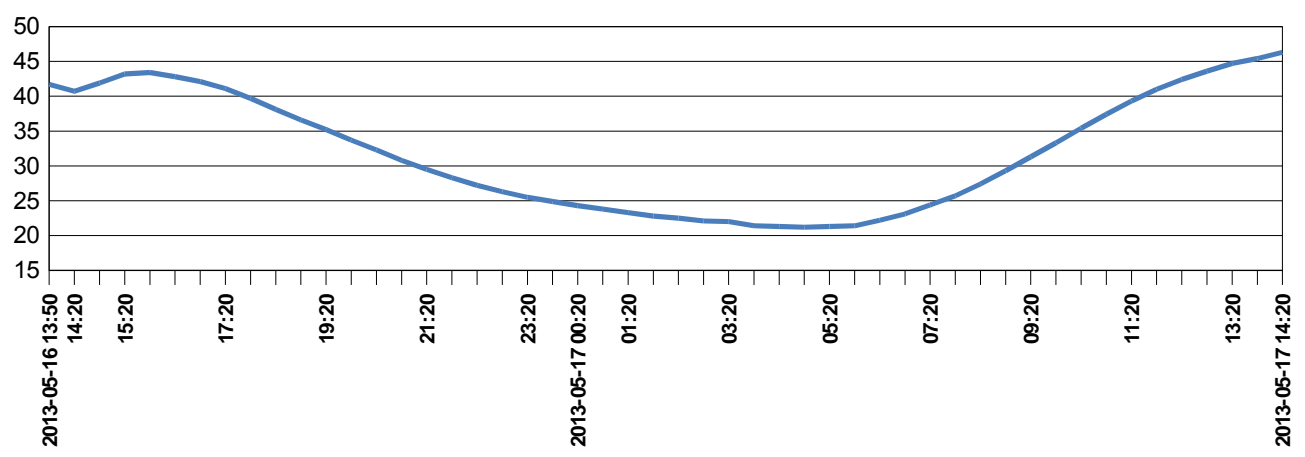

Fig. 12. Changes of temperature in ${ }^{\circ} \mathrm{C}$ 
During this session temperature variations were much higher (their amplitude equalled to $25.1^{\circ} \mathrm{C}$ ); therefore movements of the points of construction were also bigger. The maximum change in the direction of the $X$ coordinate achieved $6 \mathrm{~mm}$ for point 3. Almost identical displacements in the $X$ coordinate direction for all points suggests that the reaction of the skylight construction on temperature variations, and resulting change in geometry, is not symmetric with respect to the centre of the Main Hall. Such behaviour results from the method of supporting the construction. As it may be seen from Fig. 13, A and B supports, on which the total station is located, and point 17 create the anchorage of the skylight construction. On the contrary, the method of supporting the construction on C, D and E supports, which may be seen in Fig.14, allows for horizontal movements of the construction with respect to the support.

The distribution of displacements in the $Y$ coordinate direction is different. In this case, displacements have different signs and the symmetry of displacements with respect to the centre of the construction is well visible. Similarly to te session I, vertical displacements of particular points are slightly diversified, but they are highly correlated with temperature variations. This may be explained by the symmetry of distribution of vertical displacements with respect to the construction centre and by distribution of analysed points in similar distances from this centre (Fig. 4).

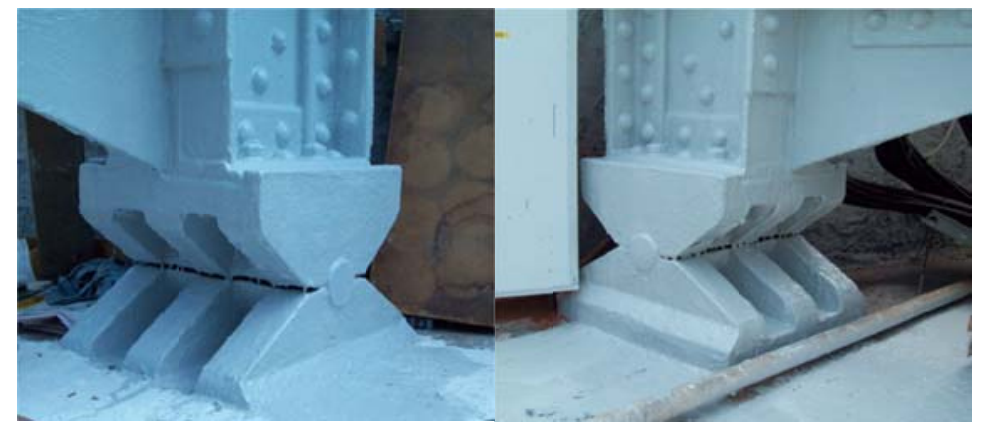

Fig. 13. Jointed mount of the construction on bearings $A$ and $B$

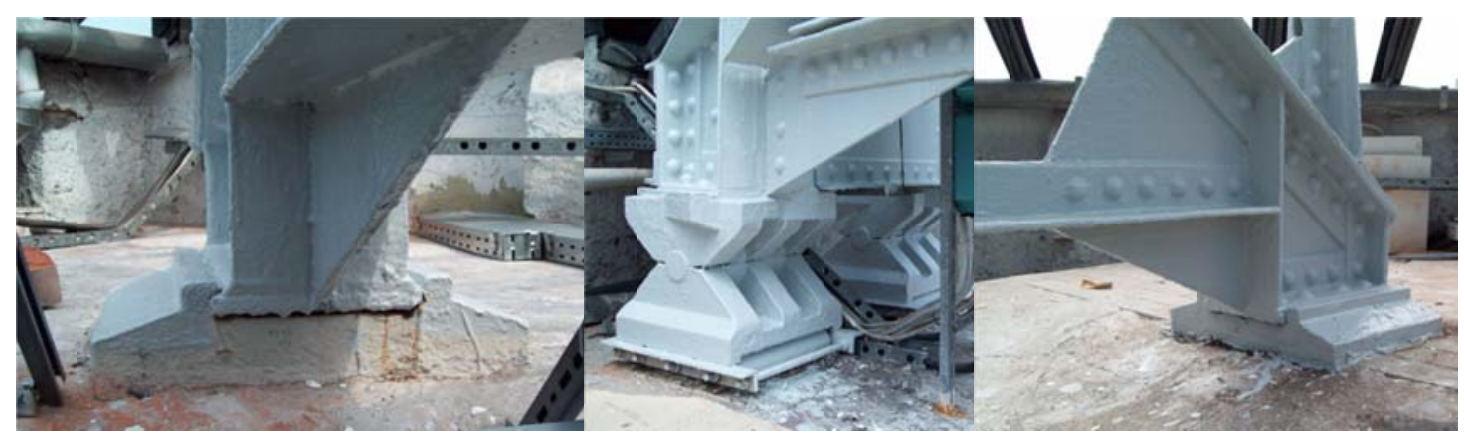

Fig. 14. Movable mount of the construction on bearings $C, D$ and $E$

The nature of displacements of points, which were determined in both sessions, was confirmed by the results of earlier research works, performed for the same object, which were described in Jastrzębski S. et al. (2008) or Odziemczyk W., Woźniak M. (2009). 


\section{Influence of the temperature on the measuring system}

Although the basic objective of measurements was to analyse movements of the skylight construction, performed measurements also allowed to obtain interesting results concerning the behaviour of elements of the measuring set in high temperature variations. In particular, changes of the collimation error value, the zero point of the vertical circle and changes of orientation of the horizontal circle, were analysed. It was possible to determine changes of the collimation value and the zero point of the vertical circle since measurements were performed in two faces. As a result of analysis of measuring data it could be concluded that temperature variations slightly influence the changes of the collimation values and the zero point of the vertical circle. The amplitude of changes during session II did not exceed $15^{c c}$, both, for the collimation and the zero point of the $V$ circle. These results confirm the considerable improvements in thermal resistance of the telescope construction, comparing to older models of instruments. Modifications in the ATR system construction, introduced in TPS1200+ series instruments are described by Kirschner H. and Stempfhuber W. (2008)

Changes in orientation of the horizontal circle may be tracked basing on measurements to reference points 1 and 7 . As a result of analysis of measurements it was stated that changes of the horizontal direction to these points are compliant, what proves the stability of the angle between them. Therefore, it was considered that changes in direction to each point resulted from the changes of the instrument itself. Since the total station was placed on a standard, wooden tripod during each of the measurements, this tripod became the most probable source of observed changes.

The diagram of changes in orientation of the instrument for session I is presented in Fig.15. Unit of orientation changes is taken as $0.1 \mathrm{mgon}$.

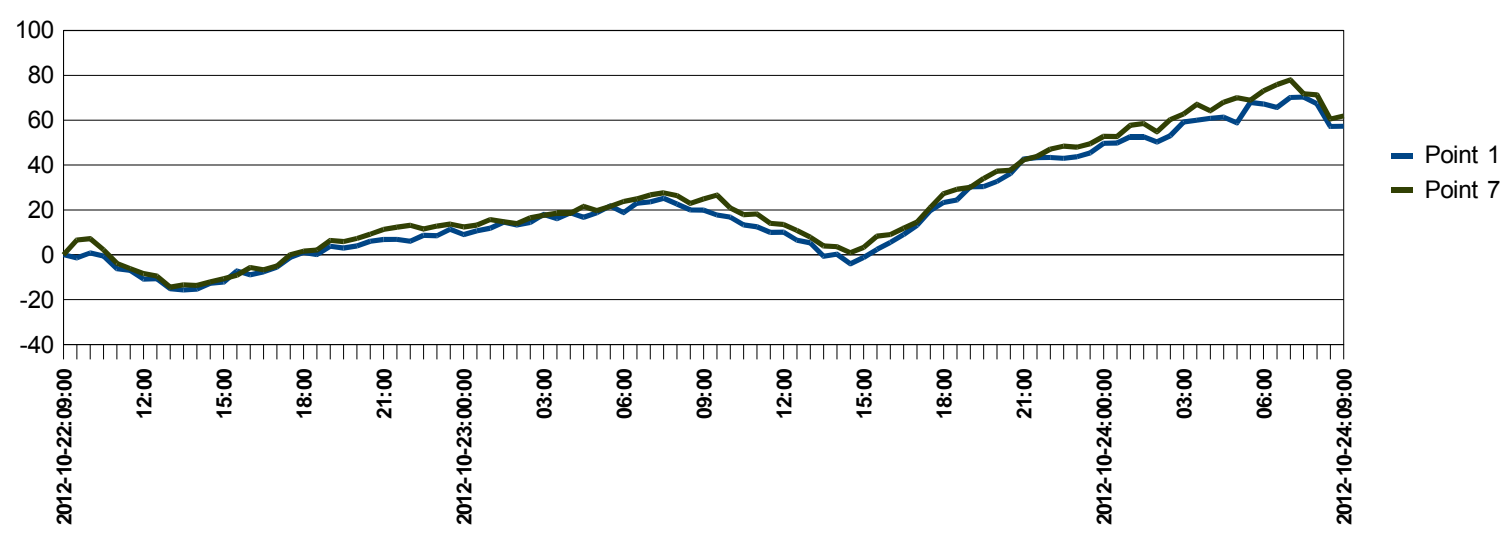

Fig. 15. Changes of horizontal orientation of the instrument

The issue of stability of geometric parameters of the measuring set will be the subject of a separate paper. 


\section{Conclusions}

Performed experiments confirmed the usefulness of the developed measuring system for monitoring deformations of constructions.

In the case of the analysed object it was very important to record the temperature, as the basic component which caused deformations. The applied solution, which consisted of utilisation of the external recorder allows to consider the influence of temperature at the stage of processing the results of measurements. Consideration of the influence of atmospheric conditions at the stage of measurements will be possible after the expansion of the system with a sensor which may be read out in real time. The example of such a sensor is Meteo sensor DTM manufactured by Leica Geosystems. We plan to expand the system with a similar sensor in the future.

Data concerning displacements of the object proved the high sensitivity of the construction to changes in temperature. Vertical displacements were of the same order as horizontal ones. The control points, placed on the skylight construction allowed to obtain the image of distribution of displacements; their location,. however, within a similar distance to the construction centre resulted in incompleteness of this image. In order to obtain the more complete information about the behaviour of the construction it would be reasonable to complement the set of control points with points located close to supports and a point located close to the construction centre.

\section{References}

Kirschner H., Stempfhuber W. (2008): The Kinematic Potential of Modern Tracking Total Stations - A State of the Art Report on the Leica TPS1200+, Proceedings of the 1st International Conference on Machine Control \& Guidance, June 24-26 Zurich Switzerland s. 51-60

Jastrzębski S., Odziemczyk W., Woźniak M., Wojciechowski J. (2008): Ivestigation of short-term roof structure deformations using geodetic methods, Reports on Geodesy, No. 1(84) 2008 s. $105-110$

Odziemczyk W., Woźniak M. (2008): TC-calc jako system zdalnego monitoringu geodezyjnego. Gliwice 2008, Wykorzystanie metod geodezyjnych w ocenie stanu geometrycznego budowli, TC-calc as a system of remote geodetic monitoring. Utilisation of geodetic methods in the assessment of geometric conditions of structures, Praca zbiorowa pod redakcją K. Kłoska i W. Prószyńskiego, Wydawnictwo Politechniki Śląskiej, s. 173-180

Odziemczyk W., Woźniak M. (2009): Monitoring of WUT grand hall roof in conditions of high temperature changes, Warszawa 2009, Reports on Geodesy, No. 1(85) 2009

Odziemczyk W. (2012): Automatyzacja procedur pomiarowych realizowanych tachimetrami systemu Leica TPS1200. Automation of measuring procedures performed using Leica TPS1200 system total stations. Poznań 2012, Inżynieryjne Zastosowania Geodezji, Monografia pod redakcją A. Plichty i I. Wyczałka, Wydawnictwo Politechniki Poznańskiej, s. 95 - 102 
Deska K. (2013): An Investigation into the Influence of a Temperature Load of a Suspended Roof in Measurements for Diagnostic Purposes, Kraków 2013, Geomatics and Environmental Engineering - Vol 7/1 2013

\section{Authors:}

Waldemar Odziemczyk ${ }^{1)}$, w.odziemczyk@gik.pw.edu.pl

1) Faculty of Geodesy and Cartography, Warsaw University of Technology, Warsaw, Poland 